\title{
Parametric Design for the Internal Gear Pairs of Double Ring Reducer Using UG
}

\author{
Qiang $X u^{1, a}$, Qisheng $X u^{1, b}$, Aihua Zhu ${ }^{2, c}$ \\ ${ }^{1}$ Department of Mechanical Engineering, Hefei University. Hefei 230601, China \\ 2 School of Mechatronics Engineering, East China Jiao tong University. Nanchang 330013, China \\ axuq618@126.com, bxqs723@sina.com, cxdy2000@126.com
}

Keywords: Double Ring Reducer, Parameter, Roll Angle, Internal Gear Pairs.

\begin{abstract}
The core parts of double ring reducer is the internal gear pairs with small tooth difference. To build the 3D parametric assembly model of the internal matins gears with small tooth difference, the internal variable $t$ of $U G$ is introduced. The roll angle formula between addendum circle and dedendum circle and the corresponding coordinate equations of the involute profile were established. By Law Curve in UG and commands such as Mirror Feature and Extrude etc, the parametric models of inner and external gears and the corresponding assembly model were created separately. The results show the assembly model varies by gear parameters, and do stable basis for the further study on the mechanism.
\end{abstract}

\section{Introduction}

A new double ring reducer is widely applied in national defense, metallurgy, mine, transportation and aerospace etc because it is of many advantages, such as with compact structure, bigger reduction ratio, ensured machining precision, less force of planetary gear bearings [1] [2].

To facilitate the optimization design of the reducer, the 3D parametric modeling of the reducer is required. The many papers introduce the 3D-modeling method of spur or helical gears in recent years, but the research on the 3D parametric modeling of profile shifted internal gear pairs is less [2-3]. The article describes the parametric modeling of the internal gear pair of the double ring reducer by using UG6.0, and makes a stable foundation for further research on the reducer.

\section{The meshing principles of double ring reducer and the constrained conditions}

The structure diagram of a new double ring reducer is shown in Figure 1, the high-speed level is composed of a pair of helical gears a b, the low-speed level consists of a planetary transmission with small tooth number difference. $\mathrm{H}$ is an active crankshaft; $\mathrm{Z} 2$ is an inner planetary gear, and $\mathrm{Z} 1$

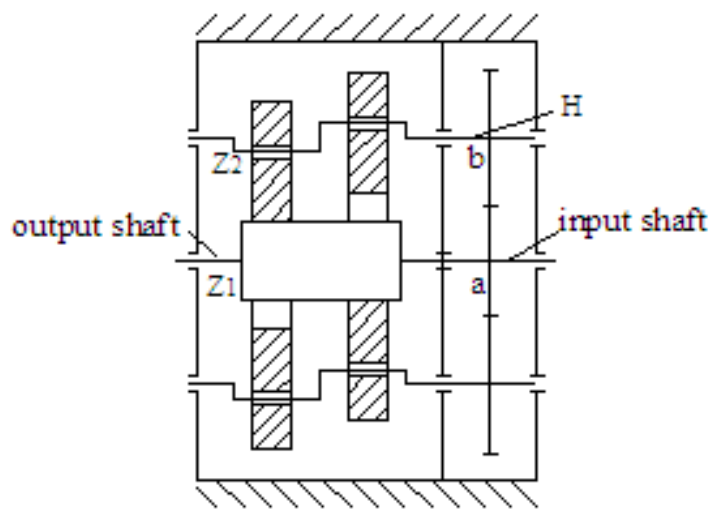

Fig. 1 The structure diagram of a new double ring reducer

Is an external gear. The inner planetary gears do translation by work principles of two-crank mechanism, a rotation motion is input from the gear a, the motion is output from the external gear 1 by bigger reduction ratio. 
In order to ensure the continuous transmission of the internal gear pairs with small tooth number difference, the contact ratio $\varepsilon$ must be more than the permitted value $[\varepsilon]$; to ensure that the internal gear pairs don't produce the tooth-overlapping inference, Gs $>0$ must be satisfied. In order to ensure internal gear tooth profile is involute tooth profile, the addendum circle diameter of the internal gear Must be more than the base circle diameter. Meanwhile the internal or external gear addendum must be of sufficient thickness, there are not undercutting phenomena at the root of the internal or external gear's tooth, the non-end cutting conditions of the internal gear machined with gear shaper must be satisfied, the concrete parameter values are obtained by looking for in 4 refs.

\section{The parametric modeling of the involute internal gear pairs with small tooth difference}

\subsection{The principle of parametric modeling}

The essence of three-dimensional parametric design is that the shape and size of parts are changed by changing designing parameters. The designing parameters of the internal gear pairs of double ring reducer are: The module $\mathrm{m}$, the modification coefficient $\mathrm{x}$, the addendum coefficient ${ }^{h_{\mathrm{a}}^{*}}$, references 5 give the calculation formula of the addendum circle and dedendum circle diameter of the external gear $Z_{1}$ or the internal gear $Z_{2}$.

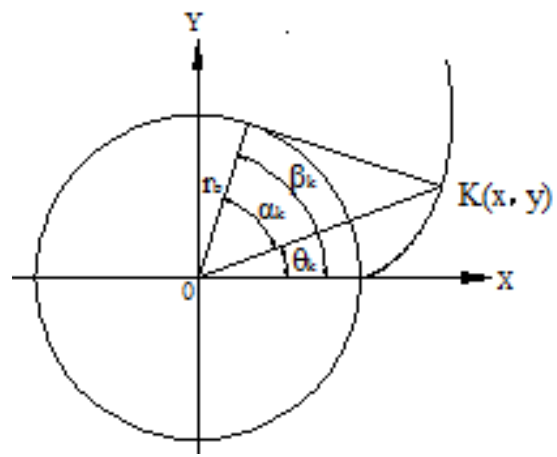

Fig. 2 the relationships between the roll angle, the pressure angle, the profile-generating angle

The profile of the involute gear is realized by 'law curve' in UG, the two requirements for using 'law curve' are the following points: First, the rectangular coordinates equations of involute profile are established; second the variables $t$ used in these equations must be in $[0,1][6]$.

If $\mathrm{rb}$ is the basic circle radius, the coordinate's equations of involute profile are [7]

$$
\left\{\begin{array}{l}
x=r_{b} \cos \beta_{k}+r_{b} \beta_{k} \sin \beta_{k} \\
y=r_{b} \sin \beta_{k}-r_{b} \beta_{k} \cos \beta_{k}
\end{array}\right.
$$

Here $\beta_{k}$ is the roll angle of one point $\mathrm{K}$ on the involute-curve

To get the tooth profile curve controlled by variable parameters, the involute curve between the addendum circle and dedendum circle must be got, that the roll angle $\beta_{f}$ on the dedendum circle and the roll angle $\beta_{a}$ on the addendum circle must be calculated.

If the intersection point of the profile with circle with any radius $r_{k}$ is $K$, the profile-generating angle of the intersection point $\mathrm{K}$ is $\theta_{\mathrm{k}}$, and the pressure angle is $\alpha_{\mathrm{k}}$ as shown in Figure 2, the roll angle on the point is as follows

$$
\left\{\begin{array}{l}
\beta_{k}=\theta_{k}+\alpha_{k} \\
\cos \alpha_{k}=r_{b} / r_{k} \\
\theta_{k}=\tan \alpha_{k}-\alpha_{k}
\end{array}\right.
$$

If $t$ is $U G$ interior variable, its varying ranges must be in $[0,1]$, the roll angle between addendum circle and dedendum circle is

$$
\beta_{\mathrm{t}}=\beta_{f}+\left(\beta_{a}-\beta_{f}\right) t
$$

As a result, the coordinate equations of the involute profile between addendum circle and dedendum circle are

$$
\left\{\begin{array}{l}
x_{t}=r_{b} \cos \beta_{t}+r_{b} \beta_{t} \sin \beta_{t} \\
y=r_{b} \sin \beta_{t}-r_{b} \beta_{t} \cos \beta_{t}
\end{array}\right.
$$




\subsection{The parameter modeling of the profile curve}

1) The expressions to create the involute profile of external gear

The basic circle diameter $\mathrm{db} 1$, the addendum circle diameter $\mathrm{da}_{1}$, the dedendum circle diameter df 1 are calculated by basic parameters of internal gear pairs, their expressions for the involute profile is as follows

alpha1 $=\arccos (\mathrm{db} 1 / \mathrm{da} 1) / /$ alpha1 is the pressure angle on the intersection point a1 of the involute profile of gear1 with the addendum circle// alphra1=Radians (alpha1) // alphra1 is alpha1 in radians// ceta1=tan (alpha1) - alphra1// ceta1 is the generating angle corresponding to the involute segment between base circle and dedendum circle, Units should be filled with constant // cetda $1=\operatorname{deg}($ ceta 1$) / /$ cetda 1 is ceta 1 in degrees $/ /$ $\mathrm{Ba} 1=$ cetda1+alpha1 // $\mathrm{Ba} 1$ is the roll angle on the intersection point a of the involute profile of gear1 with the addendum circle in degrees//

The calculation of roll angle Bfl of dedendum circle is similar to the calculation of roll angle of addendum circle and so will not be repeated here.

$\mathrm{t}=1 / / \mathrm{t}$ is the internal system variable in $\mathrm{UG} / /$

$\mathrm{Bt} 1=\mathrm{Bf} 1+(\mathrm{Ba} 1-\mathrm{Bf1}) * \mathrm{t} / / \mathrm{Bt} 1$ is the roll angle of the involute segment between addendum circle and dedendum circle in degrees//

2) Select "Sketch $>$ Sketch in Task Environment", and create reference circle, addendum circle, dedendum circle on the XOY plane.

3) Create the first involute. Because the involute expressions is already established, the first involute segment $\mathrm{S} 1$ on the XC-Y"C plane is generated by selecting "Insert-Curve-Law Curve" from the pull-down menu.

4) Create the symmetrical base plane of external gear profile. Draw a line segment $L_{1}$ arbitrarily, the line endpoint coincides with the origin by selecting "Constrain", and the another endpoint is on both the reference circle and the involute segment. Create a line segment $\mathrm{L}_{2}$ that makes the angle of 90/Z1 with the line segment $\mathrm{L}_{1}$, quit the sketch environment, create the arbitrary length segment $\mathrm{L}_{3}$ that coincides with Zc axis. Create the symmetrical base plane by selecting "Two Lines" from "Types" menu through "Datumplane".

5) Create the symmetrical involute. The second involute segment we need was got by selecting "Insert> Copy Associated> Mirror Feature".

6) Complete drawing the teeth. Select "Extrude" and "Single Curve" "Stop at Intersection" in the toolbar, check the line we need, the extrude length is tooth thickness B. Using "Pattern Feature" from the pull-down menu, "Count" is the number Z1, "Pitch Angle" is $360^{\circ} / \mathrm{Z1}$, the gear tooth profile whose teeth number is $Z 1$ can be obtained. Then extrude the dedendum circle and the extrude length is tooth thickness, the gear generated is as shown in Figure 3.

The tooth groove of the internal gear is the equivalent of the tooth profile of the external gear, the tooth profile of the internal gear is the equivalent of the tooth groove of the external gear. Therefore, the parametric modeling basic idea of inner gear profile is similar, and will not be repeated here.

\subsection{The assembly model of the internal gear pair}

In order to implement three-dimensional parametric design, all expressions used for the external and internal gear model is imported.

1) Enter into the sketch environment, the two parallel lines is created, and the distance between the two lines is the actual center distance a' .

2) Using legend "Add Components", the internal gear model is added first, the centerline of the internal gear is made coincide with a line by legend "Assembly Constrain" "Touching Align" "Auto Judge Axial Center", and then the centerline of the added external gear is made coincide with another line. The profile of the internal gear is made contact with one of the external gear by selecting "Contact"; one end of two gears is made on the same plane by selecting "Align" as shown in Figure 3. 


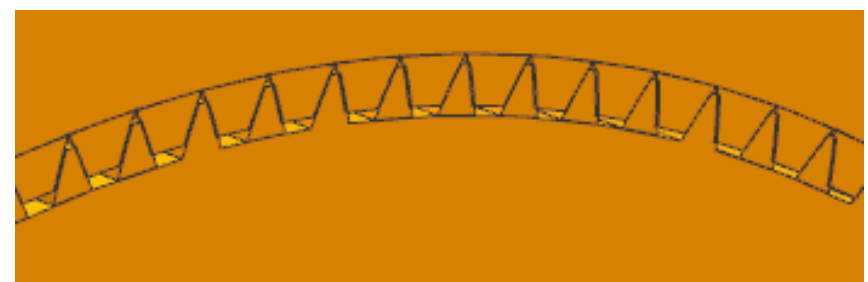

Fig. 3 the parametric assembly model of the internal gear pair

\section{Conclusion}

Following conclusions are made by studying the parametric modeling of internal gear pairs:

1) The relationships between the roll angle, the pressure angle, the profile generating angle of any point $\mathrm{K}$ on the involute-curve are analyzed, the intrinsic parameter $\mathrm{t}$ in $\mathrm{UG}$ is introduced, the formula for the roll angle of the involute profile between addendum circle and dedendum circle is established, and the coordinate equations of the involute profile is built.

2) The involute expressions of internal and external gears are established respectively, the parameter modeling of the gears is done separately, and the assembly models change with gear parameters.

\section{Acknowledgements}

Natural Science Foundation (production, science research and teaching) of Education of Anhui Province (No.KJ2012A247) and Science Foundation for Talents of Hefei University (15RC10) support this work.

\section{References}

[1]. Qiang Xu, Zhe-yin Xu, Analysis of Meshing Characteristics and Assembly Conditions of Novel Type Double Ring Reducer [J], Journal of Machine Design.Vol. 29(2012) No.2, p. 67-69.

[2]. Shu-xian Wang, Yun Wang, Li-jun Deng,et al. Parametric Design of Involute Cylintrical Helical Gear based on UG [J], Journal of Mechanical Transmission. Vol. 35 (2011) No. 5, p. 36-38.

[3]. Yu-Long Li. Quickly Realizing on Modeling an Accurate Helical Gear Used in Gear Pump based on UG Software [J]. Journal of Chinese Agricultural Mechanisation. Vol. 34 (2013) No. 5, p. 171-174.

[4]. Xu Qiang, Xu Qi-sheng, XU Dao-yi. Study on calculations of geometric dimensions and modification coefficients of planetary gear reducer of less tooth difference with biasing crankshaft based on MATLAB [J]. Advanced Materrial Research, 2012, 644(11): 298-303.

[5]. Li-hua Zhang, Yan Zeng, The new Handbook of Mechanical Design[M], Posts \& Telecom Press, 2008, p. 69-72.

[6]. Yu-long Li, Kun Liu, Zhong-fu Bao. Accurate Parameterized Modeling of Spur Involute Cilindrical Gear Used in Gear Pump Machined by Generating Method [J]. Journal of Modern Manufacture Engerating. Vol. 105 (2009) No. 11, p. 70-72.

[7]. Jian-feng Bai, Kao-tuan He. Parameterized Designing of Involute Gears based on UG [J]. Journal of Modern Manufacture Engerating. Vol. 59 (2006) No. 2, p. 118-121. 